\title{
A Survey of the Modeling of Switched Reluctance Machines and their Applications
}

\author{
Ana Camila F. Mamede ${ }^{1}$, José Roberto Camacho², \\ Rui Esteves Araújo 3 \\ ${ }^{1}$ Federal University of Uberlândia, Uberlândia, Minas Gerais, Brazil \\ (anacamilamamede@gmail.com) ORCID 0000-0002-2229-9344; ${ }^{2}$ Federal University of \\ Uberlândia, Uberlândia, Minas Gerais, Brazil (jrcamacho@ufu.br) ORCID 0000-0001-5019- \\ 5342; ${ }^{3}$ INESC TEC and Faculty of Engineering of the University of Porto, Porto, Portugal \\ (raraujo@fe.up.pt) ORCID 0000-0002-7866-9068
}

\begin{abstract}
The main objective of modeling a switched reluctance machine is to derive a mathematical function to relate the outputs to the inputs. Due to the nonlinear relationship between the variables of torque, flux linkage, current and angular position of the rotor, Switched Reluctance Machine (SRM) modeling is a very challenging task and an open problem. Modeling is usually done in two situations, modeling a single machine, or modeling a set of machines. Each one must fulfill different requirements. This work presents a survey of different SRM modeling approaches, evaluating its advantages and limitations when modeling a single machine or a set of machines.
\end{abstract}

Author Keywords. Switched Reluctance Machine, Modeling Methods, Design Methodology.

Type: Research Article

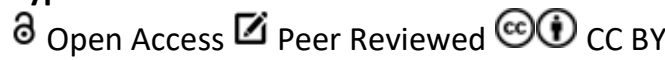

\section{Introduction}

The Switched Reluctance Machine (SRM) have inherent several advantages such as high efficiency, simple construction, robustness, high reliability, low cost, fault tolerance and absence of magnets (Ahn 2011). Due to these characteristics and despite its main disadvantages, such as: the discontinuous torque, the torque ripple, vibration and audible noise, the SRM is gaining more and more recognition in the electric drive market (Krishnan 2001).

SRMs are relatively simple electric machines but are difficult to model and control (D'Hulster et al. 2003). The SRM modeling consists of determining the flux linkage and torque characteristics. The special double salient structure, non-uniform air gap, highly saturated magnetic circuit, magnetic hysteresis and eddy current effects (Susitra and Paramasivam 2014) makes the magnetization characteristics of SRM highly non-linear (Krishnan 2001). Thus, flux linkage and torque are non-linear functions of the current and rotor position making SRM modeling a challenging task.

Usually, the modeling is done in two situations, modeling a single machine, or modeling a set of machines. The modeling of one machine aims to establish a high precision mapping between flux linkage, torque, current and rotor position for the analysis and control. For example, in the context of closed-loop sensorless SRM drives, the modeling has been used in order to avoid the use of motion sensors in the drive, and methods of flux, torque and speed estimation have been developed. These are signal-processing models of machine equations, 
which are excited by appropriate easily measurable quantities, such as phase voltages and/or currents. Such estimation algorithms generate the flux or torque which, in an ideal case, will be equal to the real quantities. Other examples are the modeling used to obtain procedures for machine parameters estimation for automatic tuning of the controller. The modeling of a set of machines is usually done in design and optimization studies and needs to be accurate and fast to determine the characteristics of SRM, since these studies usually involve iterative and retroactive processes and analyze a large volume of machines.

In this paper, the main objective is to present a critical survey of different SRM modeling methods, evaluating its advantages and limitations, helping the researcher to find the best method for its specific application. This paper has been organized as follows: the main modeling methods for a single SRM are presented in Section 2 and for a set of machines in Section 3; in Section 4 the conclusions are exposed.

\section{Modeling a Single SRM}

Switched reluctance drives are controlled by switching the phase currents on and off according to the rotor position. The most direct way to achieve this synchronism is to use a shaft position sensor feeding back the rotor position to the controller. Eliminating the sensor can improve the drive system reliability and decrease its size, weight and cost (Lyons, MacMinn, and Preston 1991). Thus, techniques were developed to provide this information to control indirectly, through modeling algorithms.

Basically, a single SRM modeling consists of mapping the relationship between flux linkage, current and rotor position. These values depend on the geometry of the machine and B-H characteristics of the lamination material. This section presents typical approaches of SRM modeling, which were divided into four categories: measurement techniques, finite element methods, analytical modeling and intelligent methods. Since the first industrial applications of SRMs in the 1970s, plenty of research showed up, mainly in the last 25 years (Matveev 2006). Figure 1 presents the modeling methods used in the last 30 years for modeling a single SRM. So a total of 100 articles were analyzed for this graph. Analytical methods have been widely used for a while, and are a good choice in some studies such as pre-design for example, but in recent years they have lost room for the accuracy and versatility of FEM and for the ability to model nonlinear systems and generalization of intelligent methods.

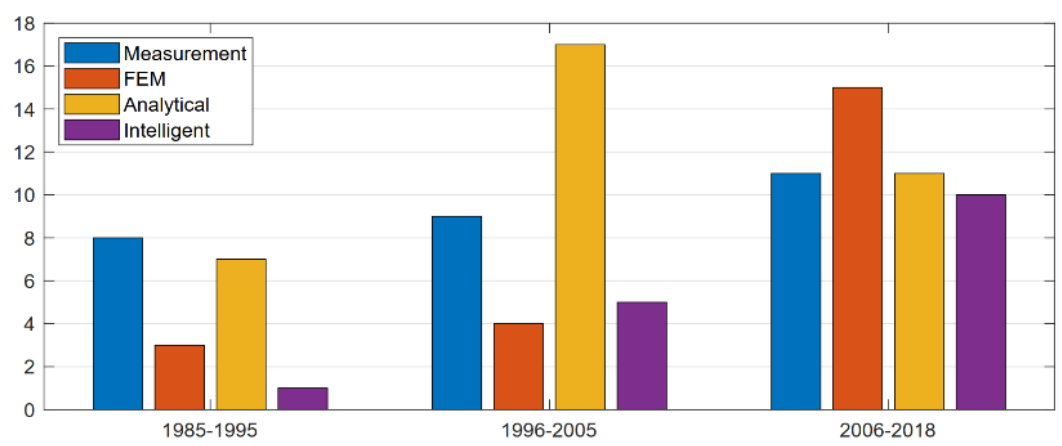

Figure 1: Papers on modeling approaches for a single SRM

\subsection{Measurement techniques}

In measurement techniques, the value of inductance, flux and torque are obtained at numerous positions underneath static or dynamic condition (Lovatt and Stephenson 1992; Gobbi, Sahoo, and Vejian 2008). These measures are acquired through a series of locked-rotor tests, which in addition to taking a long time also require the development of customized test equipment, increasing the cost and complexity of implementation (Aguado-Rojas, Maya-Ortiz, 
and Espinosa-Pérez 2018). However, because these measurements are obtained in a dynamic environment, the accuracy is high.

Measurement techniques are generally used for validation of other modeling methods, a series of papers have been published over time for this purpose (Krishnan and Materu 1989; Cheok and Ertugrul 2001; Gobbi, Sahoo, and Vejian 2008). Other works present several measurement techniques (Lovatt and Stephenson 1992; Walivadekar et al. 1996; Zhang, Cassani, and Williamson 2010). Some studies present the experimental measurement as part of an analytical model (Fahimi et al. 1998; Song, Zhang, and Ge 2015).

\subsection{Finite element methods}

As long as the geometric dimensions of the SRM are known, the characteristic values can be easily found from simulations based on any Finite Element Method (FEM) software. The FEM is able to consider all the peculiarities of SRM, such as nonlinearities and magnetic saturation, but its accuracy depends on the data entered by the user, such as the geometric dimensions of the machine and properties of the magnetic circuit material, and the choice of the elements used (Aguado-Rojas, Maya-Ortiz, and Espinosa-Pérez 2018). FEM analysis can be done using 2-D or 3-D solvers and using the recent software for finite-element magnetic analysis, the simulation of the SRM does not present much difficulty, and with a very low computational speed by a static magnetic field analysis (Song, Zhang, and Ge 2015). However, due to manufacturing tolerances and parameter variation, the phase inductance profile can substantially differ from the design data and, also, vary by up to $10 \%$ from one machine to another with the same design and rating (Tandon, Rajarathnam, and Ehsani 1997).

FEM is a useful tool during machine design and prototype testing, reducing manufacturing costs and experimental testing.

Over the years, many papers have used FEM to model SRMs through several software (Xu and Torrey 2002; Parreira et al. 2005; Srinivas and Arumugam 2005). Parreira et al. (2005) compare the FEM results for several currents with the experimental data, and noticing a significant difference for low currents compare the experimental B-H curve with that used in the FEM simulation. The observed results show a reasonable difference and it is concluded that the material used in the simulation is different from the material used in the stator and rotor construction. When correcting the B-H curve in the FEM simulation the accuracy of the results increases considerably compared to the experimental one. Figure 2 presents the experimental and simulated mean torque with the corrected $\mathrm{BH}$ curve. Therefore, the proper choice of materials is crucial for good results in FEM.

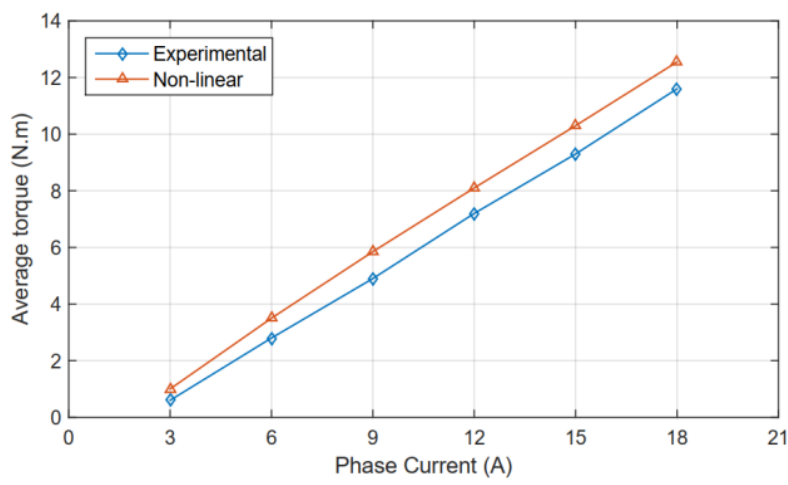

Figure 2: Average phase torque $x$ current for the experimental and FEM models

Other researchers used FEM to study design changes, different topologies (Low, Lin, and Chen 1995; Sheth and Rajagopal 2004; Sundaram, Navaneethan, and Vasanthakumar 2009) and 
different operating conditions (Faiz and Pakdelian 2006). The FEM is also massively used by other analytical models, as a parameter of comparison, basic measures and training data.

\subsection{Analytical modeling}

In analytical modeling, the SRM torque profile is derived from the precise analytical flux linkage modeling of the motor (Evangeline S, Suresh Kumar, and Jayakumar 2016). Its principal advantage is that it eases the analysis of the machine because differentiation and integration are easier to be performed (Chen et al. 2009). However, many times, to achieve good accuracy, a massive number of operations must be performed, making the computational cost of some analytical models as high as FEM.

A mathematical expression that models the machine can be obtained from the machine geometry (Hossain and Husain 2002), with magnetic field analysis (Radun 2000), magnetic equivalent circuit (Krishnan 2001), numerical curve-fitting methods (Faiz and Pakdelian 2006), using Fourier series (Andrade and Krishnan 2001) or trigonometric functions (Chi, Lin, and Chen 2005). These model's mathematical expressions can also use experimental and FEM data as input and, this way, achieve more accurate results (Fahimi et al. 1998; Chi, Lin, and Chen 2005; Song, Zhang, and Ge 2015).

\subsection{Intelligent methods}

Intelligent approximation algorithms, such as artificial neural network and fuzzy logic, are suitable for modeling nonlinear systems, and are used to estimate or model the characteristics of the SRM. In Ramamurthy, Schupbach, and Balda (2001), and Lu, Keyhani, and Fardoun (2003), an artificial neural network is used for the modeling of a SRM. In Susitra and Paramasivam (2014), techniques based on multivariate nonlinear regression and adaptive neuro fuzzy inference system are used to model the flux linkage of a SRM. Recently, studies have used least square support vector machine to establish a model for SRM, which presents excellent generalization abilities and reduced errors (Ding and Liang 2010; Evangeline S, Suresh Kumar, and Jayakumar 2016; Zhong et al. 2016).

The accuracy of these methods is conditioned mainly by observational data acquired by direct measurement or FEM. As previous system data is available and used to determine the model, generalization is possible in intelligent systems (Evangeline S, Suresh Kumar, and Jayakumar 2016). However, despite the relatively high accuracy, the required large number of data samples and considerable time to train the network is a drawback of the intelligent methods.

\subsection{Comparison and conclusions}

Table 1 summarizes and compares the modeling done by some references in relation to the method used, computational speed and accuracy. The experimental methods are not included in this table because they correspond to the actual data of the machine and are used to verify the methods.

We can observe that the intelligent methods present the best relation between accuracy and computational cost; this happens because these models use experimental data in their training and thus, present better accuracy. The computational speed depends mainly on the amount of data used for training and the method chosen.

The analytical methods under analysis present good precision, especially those that use experimental data. However, when using analytical methods, we have to be careful to choose the appropriate method, since its computational cost is sometimes similar to the intelligent methods that determine more accurate models. 


\begin{tabular}{|c|c|c|c|c|c|}
\hline References & $\begin{array}{l}\text { Modeling } \\
\text { method }\end{array}$ & $\begin{array}{c}\text { Uses external } \\
\text { data }\end{array}$ & $\begin{array}{c}\text { Computational } \\
\text { speed }\end{array}$ & Accuracy & Compared to \\
\hline Krishnan (2001) & Analytical & Not & Medium & Low & Experimental \\
\hline Fahimi et al. (1998) & Analytical & $\begin{array}{l}\text { Yes, Exp. or } \\
\text { FEM }\end{array}$ & Medium & Low & $\begin{array}{c}\text { FEM and } \\
\text { Experimental }\end{array}$ \\
\hline $\begin{array}{l}\text { Song, Zhang, and Ge } \\
\text { (2015) }\end{array}$ & Analytical & Yes & High & Medium & Experimental \\
\hline Xu and Torrey (2002) & FEM & Not & Medium & Medium & Experimental \\
\hline Parreira et al. (2005) & FEM & Yes & Low & Low & Experimental \\
\hline Chen et al. (2009) & Analytical & Yes, FEM & High & High & FEM \\
\hline Radun (2000) & Analytical & Not & Medium & Medium & Experimental \\
\hline $\begin{array}{c}\text { Ramamurthy, } \\
\text { Schupbach, and Balda } \\
\text { (2001) }\end{array}$ & Intelligent & Yes & Medium & High & Experimental \\
\hline Ding and Liang (2010) & Intelligent & Yes & Medium & High & Experimental \\
\hline Zhong et al. (2016) & Intelligent & Yes & High & High & Experimental \\
\hline
\end{tabular}

\section{Table 1: Comparison of different modeling methods of a single SRM}

Despite being subject to variations after machine construction due to manufacturing tolerances, FEM is the most appropriate method to analyze new SRM structures, such as changes in pole shapes, parameter sensitivity, among others. The FEM is the method that best represents the actual behavior of the machine before its construction.

\section{Modeling a Set of SRM}

The comparison of performance of a set of machines is part of numerous studies. Some are dedicated to finding a new topology for SRM that fits better for certain applications (Tavakkoli and Moallem 2014; Siadatan, Fatahi, and Sedaghat 2018). Many evaluate a set of machines looking for a design that achieves specific values of torque, torque ripple and efficiency for example, as in Ma and Qu (2015). Optimization studies often analyze a set of machines iteratively, resulting in a large set of machines being analyzed, so machine modeling should be fast. However, speed cannot compromise the accuracy of modeling, since it would compromise the optimization result. Figure 3 shows the modeling methods used in recent years, in 50 studies that analyze a set of SRMs, divided into three categories: finite element methods, analytical methods and intelligent methods.

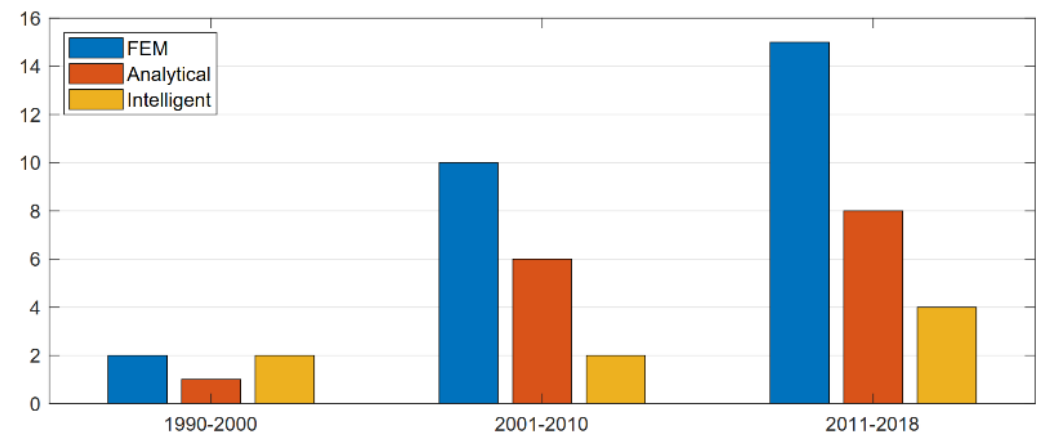

Figure 3: Papers on modeling approaches for a set of SRM

\subsection{Finite element methods}

The FEM is widely used for modeling a set of SRM, as shown in Figure 2. This happens because despite its high computational cost, FEM is an accurate and reliable method when analyzing new topologies (Tavakkoli and Moallem 2014; Siadatan, Fatahi, and Sedaghat 2018) and 
multiple criteria in the optimization (Rebahi et al. 2016). In addition, with the progress of computer technology, computational time and cost of FEM have decreased significantly.

The FEM is used in conjunction with other analytical and intelligent modeling methods. In Kechroud, Paulides, and Lomonova (2011), the FEM was used to generate the training data set for the neural network. The approach proposed in Peniak et al. (2014), combines an analytical and FEM analysis of the motor to quantify static nonlinear and dynamic performance parameters.

\subsection{Analytical modeling}

Much research has been done to improve SRM performance through project optimization (Rafajdus et al. 2014; Tavakkoli and Moallem 2014). In most of them, an optimization processor was coupled to a FEM solver to optimize the machine design, which makes the overall computational cost of the combined approaches excessive (Ma and Qu 2015). Because of this, many studies have been conducted to find an efficient modeling method that can eliminate FEM in pursuit of an optimal design (Kano, Kosaka, and Matsui 2010; Yao 2017).

Kano, Kosaka, and Matsui (2010) perform an SRM optimization and obtain the fitness evaluation, using a dynamic simulator based on the analytical interpretation of the magnetization curves and a geometric flux tube-based nonlinear magnetic analysis designed especially for SRM. At the end of the process, a prototype is fabricated according to the optimized design parameters; Figure 4 shows the calculated and measured magnetization curves for the SRM, as well as the measured and calculated energy conversion loop. It is obvious that there is a difference between the results and, as concluded by the author, a more accurate model must be determined mainly in relation to the losses and the calculation of the efficiency.

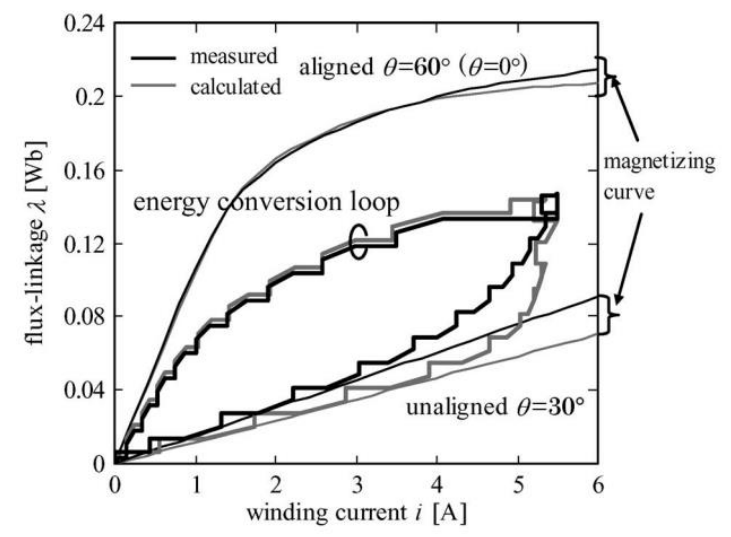

Figure 4: Comparison of the calculated and measured energy conversion loops (Kano, Kosaka, and Matsui 2010)

Some authors have developed analytical approaches that use FEM-derived data and achieve good accuracy with a controlled computational cost, since FEM use has been reduced (Peniak et al. 2014; Rafajdus et al. 2014).

\subsection{Intelligent methods}

The intelligent approach methods are another alternative used to replace the FEM in the modeling of a set of SRMs. In Kechroud, Paulides, and Lomonova (2011), the b-spline neural network is used to model the flux linkage as a function of both the rotor current and position, the training data are obtained through FEM. In Şahin, Bülent Ertan, and Leblebicioğlu (2000), the training data of the neural network are obtained from numerical field solution for doublysalient geometries. 
The use of intelligent methods for modeling a set of SRMs has increased over time, but is still low when compared to other methods. The drawback of these methods is that they need data determined by other modeling methods, making the overall computational cost high.

\subsection{Comparison and conclusions}

Table 2 presents some of the characteristics of works that carried out the modeling of a set of SRM. Most of the works do the SRM optimization and do not provide all the information, such as the simulation time and the quantity of SRM analyzed. The optimization methods used are Particle Swarm Optimization (PSO), Genetic Algorithm (GA), Differential Evolution (DE), Neural network (NN), among others.

The comparison of results is compromised by the construction of the machine and experimental validation, a challenge for most of the works due to the costs involved in this process. Kano, Kosaka, and Matsui (2010) used the analytical expressions for modeling the machines, and at the end of the optimization process, the machine was built and the modeling was compared with experimental data, presenting good results.

Most of the works did not provide information about the simulation time and amount of SRM modeled, which makes it impossible to compare the computational cost of the work. Kano, Kosaka, and Matsui (2010) seems to be faster because it analyzes more variables in less time, however, as the amount of SRM analyzed by Peniak et al. (2014) was not available, this can be a questionable conclusion.

\begin{tabular}{|c|c|c|c|c|c|c|}
\hline References & $\begin{array}{c}\text { Modeling } \\
\text { method }\end{array}$ & $\begin{array}{c}\text { Uses external } \\
\text { data }\end{array}$ & $\begin{array}{c}\text { Simulation } \\
\text { time }\end{array}$ & $\begin{array}{l}\text { Number of } \\
\text { variables }\end{array}$ & $\begin{array}{l}\text { Quantity of } \\
\text { SRM }\end{array}$ & $\begin{array}{c}\text { Optimization } \\
\text { method }\end{array}$ \\
\hline $\begin{array}{l}\text { Tavakkoli and } \\
\text { Moallem (2014) }\end{array}$ & FEM & Not & $\mathrm{N} / \mathrm{A}$ & 8 & 18 & Taguchi \\
\hline Ma and Qu (2015) & Intelligent & Yes, FEM & N/A & 7 & 240 & PSO \\
\hline Rebahi et al. (2016) & FEM & Not & N/A & 4 & +1000 & PSO, GA e DE \\
\hline $\begin{array}{l}\text { Kechroud, Paulides, } \\
\text { and Lomonova } \\
\text { (2011) }\end{array}$ & Intelligent & Yes, FEM & $\mathrm{N} / \mathrm{A}$ & 2 & N/A & $\begin{array}{l}\text { Levenberg- } \\
\text { Marquadt }\end{array}$ \\
\hline Peniak et al. (2014) & Analytical & Yes, FEM & $72 \mathrm{~h}$ & 7 & $\mathrm{~N} / \mathrm{A}$ & $\begin{array}{c}\text { Opera } \\
\text { optimizer }\end{array}$ \\
\hline $\begin{array}{l}\text { Kano, Kosaka, and } \\
\text { Matsui (2010) }\end{array}$ & Analytical & Not & $66 \mathrm{~h}$ & 10 & +6000 & GA \\
\hline Yao (2017) & Analytical & Not & N/A & 9 & N/A & GA \\
\hline $\begin{array}{l}\text { Şahin, Bülent Ertan, } \\
\text { and Leblebicioğlu } \\
\text { (2000) }\end{array}$ & Intelligent & Yes & $\mathrm{N} / \mathrm{A}$ & 5 & N/A & NN \\
\hline
\end{tabular}

Table 2: Comparison of different modeling methods for a set of SRM

\section{Conclusions}

This article presented a survey of SRM modeling in the last three decades. To simplify, the modeling was divided into two categories, modeling a single SRM and a set of SRMs, since it is understood that each one must fulfill different requirements. Table 1 and Table 2 summarize the modeling approaches discussed in this survey paper, organized by features that are compared.

For the modeling of a single SRM, a certain balance between the methods used in the last 10 years was observed. The modeling method is generally chosen according to the limitations of each study, measurement techniques are ideal but expensive. Therefore, the other modeling approaches are used and present satisfactory accuracy and low cost. 
The modeling of a set of SRMs seeks a good relation between accuracy and computational cost. As these studies usually involve comparing performance across multiple machines, accuracy is paramount. Although the FEM still dominates this type of application, the other methods have grown in number of works and quality of results.

Despite the number of models presented in the literature, the modeling of the switched reluctance machine still remains an open problem. The graphs presented in this paper corroborate this, a large volume of work on SRM modeling has been published in the last decade. It is our hope that this survey paper of modeling techniques of SRM acts as a reference guide for both modeling-driven engineers and researchers.

\section{References}

Aguado-Rojas, M., P. Maya-Ortiz, and G. Espinosa-Pérez. 2018. "On-line estimation of switched reluctance motor parameters". International Journal of Adaptive Control and Signal Processing 32, no. 6 (april): 950-66. https://doi.org/10.1002/acs.2877.

Ahn, JIn-Woo. 2011. "Switched reluctance motor". In Torque Control, edited by M. T. Lamchich, 201-52. IntechOpen. https://doi.org/10.5772/10520.

Andrade, D. A., and R. Krishnan. 2001. "Characterization of switched reluctance machines using Fourier series approach". In Conference Record of the 2001 IEEE Industry Applications Conference. 36th IAS Annual Meeting, 48-54. IEEE. https://doi.org/10.1109/IAS.2001.955391.

Chen, H., D. Jiang, J. Yang, and L. Shi. 2009. "A new analytical model for switched reluctance motors". IEEE Transactions on Magnetics 45, no. 8 (august): 3107-13. https://doi.org/10.1109/TMAG.2009.2015876.

Cheok, A. D., and N. Ertugrul. 2001. "Computer-based automated test measurement system for determining magnetization characteristics of switched reluctance motors". IEEE Transactions on Instrumentation and Measurement 50, no. 3 (june): 690-96. https://doi.org/10.1109/19.930441.

Chi, H. P., R. L. Lin, and J. F. Chen. 2005. "Simplified flux-linkage model for switched-reluctance motors". IEE Proceedings: Electric Power Applications 152, no. 3 (may): 577-83. https://doi.org/10.1049/ip-epa:20045207.

D'Hulster, F., K. Stockman, J. Desmet, and R. Belmans. 2003. "Advanced nonlinear modelling techniques for switched reluctance machines". In Proceedings of the IASTED International Conference on Modelling, Simulation and Optimization, 44-51. IASTED/ACTA Press.

Ding, W., and D. Liang. 2010. "Least square support vector machine network-based modeling for switched reluctance starter/generator". International Journal of Applied Electromagnetics and Mechanics 33, no. 1-2: 403-13. https://doi.org/10.3233/JAE-20101139.

Evangeline S, J., S. Suresh Kumar, and J. Jayakumar. 2016. "Torque modeling of Switched Reluctance Motor using LSSVM-DE". Neurocomputing 211, (october): 117-28. https://doi.org/10.1016/j.neucom.2016.02.076.

Fahimi, B., G. Suresh, J. Mahdavi, and M. Ehsami. 1998. "A new approach to model switched reluctance motor drive application to dynamic performance prediction, control and design". In PESC 98 Record. 29th Annual IEEE Power Electronics Specialists Conference, 2097-102. IEEE. https://doi.org/10.1109/PESC.1998.703469. 
Faiz, J., and S. Pakdelian. 2006. "Finite element analysis of switched reluctance motor under dynamic eccentricity fault". In 12th International Power Electronics and Motion Control Conference: Proceedings, 1042-46. IEEE. https://doi.org/10.1109/EPEPEMC.2006.4778538.

Gobbi, R., N. C. Sahoo, and R. Vejian. 2008. "Experimental investigations on computer-based methods for determination of static electromagnetic characteristics of switched reluctance motors". IEEE Transactions on Instrumentation and Measurement 57, no. 10 (may): 2196211. https://doi.org/10.1109/TIM.2008.922095.

Hossain, S. A., and I. Husain. 2002. "A geometry based simplified analytical model of switched reluctance machines for real-time controller implementation". In IEEE 33rd Annual IEEE Power Electronics Specialists Conference: Proceedings, 839-44. IEEE. https://doi.org/10.1109/PSEC.2002.1022558.

Kano, Y., T. Kosaka, and N. Matsui. 2010. "Optimum design approach for a two-phase switched reluctance compressor drive". IEEE Transactions on Industry Applications 46, no. 3 (may): 955-64. https://doi.org/10.1109/TIA.2010.2045212.

Kechroud, A., J. J. H. Paulides, and E. A. Lomonova. 2011. "B-spline neural network approach to inverse problems in switched reluctance motor optimal design". IEEE Transactions on Magnetics 47, no. 10 (october): 4179-82. https://doi.org/10.1109/TMAG.2011.2151183.

Krishnan, R. 2001. Switched reluctance motor drives: Modeling, simulation, analysis, design, and applications. Boca Raton: CRC Press. https://doi.org/10.1201/9781420041644.

Krishnan, R., and P. Materu. 1989. "Measurement and instrumentation of a switched reluctance motor". In Conference Record of the IEEE Industry Applications Society Annual Meeting, 116-21. IEEE. https://doi.org/10.1109/IAS.1989.96639.

Lovatt, H. C., and J. M. Stephenson. 1992. "Measurement of magnetic characteristics of switched-reluctance motors". In International Conference on Electric Machines, 465-69. http://hdl.handle.net/102.100.100/249747?index=1.

Low, T. S., H. Lin, and S. X. Chen. 1995. "Analysis and comparison of switched reluctance motors with different physical sizes using a 2D finite element method". IEEE Transactions on Magnetics 31, no. 6 (november): 3503-05. https://doi.org/10.1109/20.489550.

Lu, W., A. Keyhani, and A. Fardoun. 2003. "Neural network-based modeling and parameter identification of switched reluctance motors". IEEE Transactions on Energy Conversion 18, no. 2 (june): 284-90. https://doi.org/10.1109/TEC.2003.811738.

Lyons, J. P., S. R. MacMinn, and M. A. Preston. 1991. "Flux-current methods for SRM rotor position estimation". In Conference Record of the 1991 IEEE Industry Applications Society Annual Meeting, 482-87. IEEE. https://doi.org/10.1109/IAS.1991.178199.

Ma, C., and L. Qu. 2015. "Multiobjective optimization of switched reluctance motors based on design of experiments and particle swarm optimization". IEEE Transactions on Energy Conversion 30, no. 3 (september): 1144-53. https://doi.org/10.1109/TEC.2015.2411677.

Matveev, A. 2006. "Development of methods, algorithms and software for optimal design of switched reluctance drivers". Phd diss., Technische Universiteit Eindhoven. https://doi.org/10.6100/IR600499.

Parreira, B., S. Rafael, A. J. Pires, and P. J. Costa Branco. 2005. "Obtaining the magnetic characteristics of an 8/6 switched reluctance machine: From FEM analysis to the experimental tests". IEEE Transactions on Industrial Electronics 52, no. 6 (december): 163543. https://doi.org/10.1109/TIE.2005.858709. 
Peniak, A., J. Makarovič, P. Rafajdus, and P. Dúbravka. 2014. "Optimization of switched reluctance motor for drive system in automotive applications". International Journal of Energy and Power Engineering 8, no. 9: 1554-61. https://doi.org/10.5281/zenodo.1094737.

Radun, A. 2000. "Analytically computing the flux linked by a switched reluctance motor phase when the stator and rotor poles overlap". IEEE Transactions on Magnetics 36, no. 4 PART 2: 1996-2003. https://doi.org/10.1109/20.875277.

Rafajdus, P., A. Peniak, D. Peter, P. Makys, and L. Szabo. 2014. "Optimization of switched reluctance motor design procedure for electrical vehicles". In 2014 International Conference on Optimization of Electrical and Electronic Equipment, OPTIM 2014, 397-404. IEEE. https://doi.org/10.1109/OPTIM.2014.6851033.

Ramamurthy, S. S., R. M. Schupbach, and J. C. Balda. 2001. "Artificial neural networks based models for the multiply excited Switched Reluctance Motor". In APEC 2001: Sixteenth Annual IEEE Applied Power Electronics Conference and Exposition, 1109-15. IEEE. https://doi.org/10.1109/APEC.2001.912505.

Rebahi, F., A. Bentounsi, H. Bouchekara, and R. Rebbah. 2016. "Optimization design of a doubly salient $8 / 6$ SRM based on three computational intelligence methods". Turkish Journal of Electrical Engineering and Computer Sciences 24, no. 5: 4454-64. https://doi.org/10.3906/elk-1503-142.

Şahin, F., H. Bülent Ertan, and K. Leblebicioğlu. 2000. "Optimum geometry for torque ripple minimization of switched reluctance motors". IEEE Transactions on Energy Conversion 15, no. 1 (march): 30-39. https://doi.org/10.1109/60.849113.

Sheth, N. K., and K. R. Rajagopal. 2004. "Torque profiles of a switched reluctance motor having special pole face shapes and asymmetric stator poles". IEEE Transactions on Magnetics 40, no. 4 II (july): 2035-37. https://doi.org/10.1109/TMAG.2004.829841.

Siadatan, A., N. Fatahi, and M. Sedaghat. 2018. "Optimum designed multilayer switched reluctance motors for use in electric vehicles to increase efficiency". In SPEEDAM 2018 Proceedings: International Symposium on Power Electronics, Electrical Drives, Automation and Motion, 304-08. IEEE. https://doi.org/10.1109/SPEEDAM.2018.8445215.

Song, S., M. Zhang, and L. Ge. 2015. "A new fast method for obtaining flux-linkage characteristics of SRM". IEEE Transactions on Industrial Electronics 62, no. 7 (july): 4105-17. https://doi.org/10.1109/TIE.2015.2390147.

Srinivas, K. N., and R. Arumugam. 2005. "Analysis and characterization of Switched reluctance motors: Part I - dynamic, static, and frequency spectrum analyses". IEEE Transactions on Magnetics 41, no. 4 (april): 1306-20. https://doi.org/10.1109/TMAG.2004.843334.

Sundaram, M., P. Navaneethan, and M. Vasanthakumar. 2009. "Magnetic analysis and comparison of Switched Reluctance Motors with different stator pole shapes using a 3D finite element method". Paper presented in the 2009 International Conference on Control, Automation, Communication and Energy Conservation, Perundurai, Tamilnadu, India, 4-6 June 2009. https://ieeexplore.ieee.org/document/5204380.

Susitra, D., and S. Paramasivam. 2014. "Non-linear flux linkage modeling of switched reluctance machine using MVNLR and ANFIS". Journal of Intelligent and Fuzzy Systems 26, no. 2: 759-68. https://doi.org/10.3233/IFS-130766.

Tandon, P., A. V. Rajarathnam, and M. Ehsani. 1997. "Self-tuning control of a switchedreluctance motor drive with shaft position sensor". IEEE Transactions on Industry Applications 33, no. 4: 1002-10. https://doi.org/10.1109/28.605742. 
Tavakkoli, M., and M. Moallem. 2014. "Optimum rotor shaping for torque improvement of double stator switched reluctance motor". Journal of Electrical Engineering and Technology 9, no. 4 (july): 1315-23. https://doi.org/10.5370/JEET.2014.9.4.1315.

Walivadekar, V. N., S. K. Pillai, S. S. Sadistap, and R. Bhandhari. 1996. "PC based data acquisition system for measurement of switched reluctance motor (SRM)". In Proceedings of International Conference on Power Electronics, Drives and Energy Systems for Industrial Growth, 957-63. IEEE. https://doi.org/10.1109/PEDES.1996.536401.

$\mathrm{Xu}, \mathrm{Y}$., and D. A. Torrey. 2002. "Study of the mutually coupled switched reluctance machine using the finite element-circuit coupled method". IEE Proceedings: Electric Power Applications 149, no. 2 (march): 81-86. https://doi.org/10.1049/ip-epa:20020108.

Yao, W. S. 2017. "Rapid optimization of double-stators switched reluctance motor with equivalent magnetic circuit". Energies 10, no. 10 (october). https://doi.org/10.3390/en10101603.

Zhang, P., P. A. Cassani, and S. S. Williamson. 2010. "An accurate inductance profile measurement technique for switched reluctance machines". IEEE Transactions on $\begin{array}{lllll}\text { Industrial Electronics 57, no. } 9 & \text { (september): } 2972-79 .\end{array}$ https://doi.org/10.1109/TIE.2010.2048831.

Zhong, R., Y. Xu, Y. Cao, X. Guo, W. Hua, S. Xu, and W. Sun. 2016. "Accurate model of switched reluctance motor based on indirect measurement method and least square support vector machine". IET Electric Power Applications 10, no. 9 (november): 916-22. https://doi.org/10.1049/iet-epa.2016.0112. 